\title{
High Performance Liquid Chromatographic Assay for the Simultaneous Determination of Posaconazole and Vincristine in Rat Plasma
}

\author{
Hadeel A. Khalil, ${ }^{1}$ Ahmed F. El-Yazbi, ${ }^{2}$ Tarek S. Belal, ${ }^{1}$ and Dalia A. Hamdy ${ }^{1}$ \\ ${ }^{1}$ Pharmaceutical Analytical Chemistry Department, Faculty of Pharmacy, Alexandria University, Alexandria 21521, Egypt \\ ${ }^{2}$ Department of Pharmacology, Faculty of Pharmacy, Alexandria University, Alexandria 21521, Egypt
}

Correspondence should be addressed to Dalia A. Hamdy; dr.daliahamdy@gmail.com

Received 27 October 2015; Revised 28 November 2015; Accepted 2 December 2015

Academic Editor: David M. Lubman

Copyright (C) 2015 Hadeel A. Khalil et al. This is an open access article distributed under the Creative Commons Attribution License, which permits unrestricted use, distribution, and reproduction in any medium, provided the original work is properly cited.

Purpose. Developing a validated HPLC-DAD method for simultaneous determination of posaconazole (PSZ) and vincristine (VCR) in rat plasma. Methods. PSZ, VCR, and itraconazole (ITZ) were extracted from $200 \mu \mathrm{L}$ plasma using diethyl ether in the presence of $0.1 \mathrm{M}$ sodium hydroxide solution. The organic layer was evaporated in vacuo and dried residue was reconstituted and injected through HC-C18 $(4.6 \times 250 \mathrm{~mm}, 5 \mu \mathrm{m})$ column. In the mobile phase, acetonitrile and $0.015 \mathrm{M}$ potassium dihydrogen orthophosphate (30:70 to $80: 20$, linear gradient over 7 minutes) pumped at $1.5 \mathrm{~mL} / \mathrm{min}$. VCR and PSZ were measured at 220 and $262 \mathrm{~nm}$, respectively. Two Sprague Dawley rats were orally dosed PSZ followed by iv dosing of VCR and serial blood sampling was performed. Results. VCR, PSZ, and ITZ were successfully separated within $11 \mathrm{~min}$. Calibration curves were linear over the range of $50-5000 \mathrm{ng} / \mathrm{mL}$ for both drugs. The CV\% and \% error of the mean were $\leq 18 \%$ and limit of quantitation was $50 \mathrm{ng} / \mathrm{mL}$ for both drugs. Rat plasma concentrations of PSZ and VCR were simultaneously measured up to $72 \mathrm{~h}$ and their calculated pharmacokinetics parameters were comparable to the literature. Conclusion. The assay was validated as per ICH guidelines and is appropriate for pharmacokinetics drug-drug interaction studies.

\section{Introduction}

Vincristine (VCR) is a mitotic inhibitor antineoplastic agent that is used mainly in combination chemotherapy regimens for acute and chronic leukemia, lymphomas, including Hodgkin's disease and non-Hodgkin's lymphomas, and multiple myeloma [1]. Posaconazole (PSZ) is an oral triazole antifungal used in the treatment of severe oropharyngeal candidiasis, invasive aspergillosis, and other fungal infections in patients who are resistant to, or intolerant of, other antifungal drugs. PSZ is also given for prophylaxis in patients who are at high risk for invasive fungal disease due to immunosuppression, such as haematopoietic stem cell transplant recipients with graft-versus-host disease, or those with haematological malignancies with prolonged neutropenia as a result of chemotherapy $[1,2]$. The coadministration of azoles (as prophylaxis or treatment of fungal infections) and VCR has been shown to increase VCR neurotoxic effects due to the inhibition of cytochrome P450 (CYP) isoform 3A4, for which VCR is a substrate [2]. Those neurotoxic symptoms usually appear as constipation and peripheral neurotoxicity [3]. In addition, few case reports have illustrated the possible exacerbation of VCR toxicity by coadministration of PSZ in children and young adults where fluctuations in level of consciousness and seizures have been observed [4].

PSZ has been determined in human plasma samples using capillary electrophoresis [5], HPLC with fluorescence detection [6], and HPLC-tandem mass spectrometry (HPLC-MSMS) methods [7, 8]. Additionally, the simultaneous determination of azole antifungals including PSZ in plasma/serum samples gained a growing interest in the past few years. Different chromatographic methods have been described for this task such as micellar electrokinetic chromatography (MEKC) [9] and several liquid chromatographic methods coupled with tandem mass spectrometry $[10,11]$, fluorescence detection [12], and UV detection [13-16]. On the other 
hand, estimation of VCR in plasma samples has been carried out using HPLC-UV detection [17, 18], UPLC-MS-MS [19], and several HPLC-MS-MS methods [20-23]. Besides, an HPLC-MS-MS method was presented for the simultaneous determination of VCR and actinomycin-D in human dried blood spots [24]. In addition, quantification of intracellular VCR concentrations in children with acute lymphoblastic leukemia has been described using HPLC with electrochemical detection procedure [25]. Moreover, capillary zone electrophoresis coupled with electrochemical detection has been employed to study the uptake kinetics of VCR by human erythrocytes [26]. Finally, pharmacokinetics of PSZ and VCR in rats have been separately discussed in only two published reports [27, 28].

Although PSZ-VCR drug-drug interaction has been exposed in several previous reports, the concurrent determination of PSZ and VCR has not been tackled yet since no analytical reports can be found in the literature. In this report, we describe the first simple and reliable RP-HPLC with diode array detection procedure for the simultaneous determination of PSZ and VCR in rat plasma. The structurally related azole antifungal drug (itraconazole, ITZ) has been used as an internal standard. The proposed method has been applied in a preliminary pharmacokinetics drug interaction study in rats. An analytical method capable of simultaneously measuring two drugs would be a valuable tool, facilitating the measurement of pharmacokinetics using a single blood draw for each time point with no need to split the sample for processing through two assay methods. In serial blood collection studies involving rats, in particular, this is an important consideration due to the need to keep cumulative blood volume withdrawal to a minimum.

\section{Experimental}

2.1. Materials and Reagents. Posaconazole and vincristine sulfate powders (purity $>99 \%$ for both) were purchased from Selleckchem (Houston, TX, USA). Itraconazole was a kind gift from Nifty Labs Pvt. Ltd., Hyderabad, India. HPLC grade methanol and acetonitrile (Fisher Scientific UK Limited, Loughborough, Leicestershire, UK), analytical grade potassium dihydrogen orthophosphate (Riedelde-Haën, Germany), and high purity distilled water were used. Noxafil oral suspension labeled to contain $40 \mathrm{mg} / \mathrm{mL}$ PSZ (Patheon Inc., Ontario, Canada,) was purchased from Schering-Plough S.A. Vincarine vials labeled to contain $1 \mathrm{mg} / \mathrm{mL}$ vincristine sulfate solution (EIMC United Pharmaceuticals, Badr city, Cairo, Egypt) were obtained from the local market.

2.2. Chromatographic Conditions. The HPLC-DAD system consisted of Agilent 1200 series (autoinjector, quaternary pump, vacuum degasser and diode array, and multiple wavelength detectors G1315 C/D and G1365 C/D) connected to a computer loaded with Agilent ChemStation Software (Agilent Technologies, Santa Clara, CA, USA). The DAD wavelength was set at 220 and $262 \mathrm{~nm}$. The chromatographic separation was achieved using a HC-C18 $(4.6 \times 250 \mathrm{~mm}, 5 \mu \mathrm{m}$ particle size $)$ column attached to $\mathrm{HC}-\mathrm{C} 18(4.6 \times 12.5 \mathrm{~mm}$, $5 \mu \mathrm{m}$ particle size) guard column (Agilent Technologies, Santa Clara, CA, USA). The gradient elution composed the mobile phase: acetonitrile and $0.015 \mathrm{M}$ potassium dihydrogen orthophosphate $(30: 70$ to $80: 20$, linear over 7 minutes) pumped at $1.5 \mathrm{~mL} / \mathrm{min}$. Injection volume was $80 \mu \mathrm{L}$. All determinations were performed at $25^{\circ} \mathrm{C}$.

2.3. Stock and Standard Solutions. Stock solutions of PSZ and VCR sulphate $(100 \mathrm{mg} / \mathrm{L})$ were separately prepared in methanol. A $10 \mathrm{mg} / \mathrm{L}$ stock solution of the internal standard (ITZ) was prepared in methanol. To prepare samples for the calibration curves and validation assessment, three working standard solutions $(10,1$, and $0.1 \mathrm{mg} / \mathrm{L})$ of PSZ and VCR were prepared freshly by successive $1 / 10$ dilutions of the stock solutions with methanol.

2.4. Extraction Procedure. The ITZ $(0.03 \mathrm{~mL})$ was added to each $0.2 \mathrm{~mL}$ rat plasma sample in a glass test tube. To the rat plasma sample, $0.03 \mathrm{~mL}$ of $0.1 \mathrm{M} \mathrm{NaOH}$ and $6 \mathrm{~mL}$ of diethyl ether were added. Because methanol was present in the standard curve samples, an equivalent amount was added to the test samples as well $(0.2 \mathrm{~mL})$. The tubes were covered, vortex-mixed for $2 \mathrm{~min}$ at high speed, and then subsequently centrifuged for $10 \mathrm{~min}$ at $\sim 2500 \times \mathrm{g}$. The organic layer was transferred to new glass tubes and evaporated to dryness in vacuo (Christ rotational vacuum concentrator, Germany). The tubes were placed in a $-20^{\circ} \mathrm{C}$ freezer until analysis time. The residues were reconstituted in $100 \mu \mathrm{L}$ methanol of which $80 \mu \mathrm{L}$ volumes were injected into the HPLC.

2.5. Recovery. The plasma recoveries were determined for PSZ, VCR, and ITZ at concentration level $2500 \mathrm{ng} / \mathrm{mL}$ in rat plasma using four replicates for each concentration. The extraction efficiency was determined by comparing the peak areas of each analyte to the peak areas of the same amounts directly injected to the instrument without extraction.

2.6. Validation. Calibration curves were constructed using samples of $0.2 \mathrm{~mL}$ rat plasma containing PSZ, VCR, and IS. The curve ranged from 50 to $5000 \mathrm{ng} / \mathrm{mL}$ for both PSZ and VCR. The ratios of PSZ and VCR peak areas to IS peak area were calculated and plotted versus the expected PSZ or VCR concentrations. Owing to the wide range of concentrations, the calibration curve data were weighed by a factor of $1 / x^{2}$ for both drugs. Intraday accuracy and precision of the assay were determined using four sample replicates of 50, 500, and $2500 \mathrm{ng} / \mathrm{mL}$ for each of PSZ and VCR in rat plasma in the same day. The same concentrations were analyzed in three separate days for assessment of the interday accuracy and precision. For each daily run, concentrations were determined by comparison with a calibration curve prepared simultaneously on the same day of analysis. Precision was determined using percentage coefficient of variation (CV\%) and bias was assessed using percentage error of the mean.

2.7. Application to a Drug Interaction PK Study. To evaluate the applicability of this method in vivo, two rats (200-250 g) 
were given $40 \mathrm{mg} / \mathrm{kg}$ PSZ orally followed by $0.1 \mathrm{mg} / \mathrm{kg}$ VCR i.v. through the tail vein after $30 \mathrm{~min}$ of oral dosing. The protocol was approved by the Ethics Committee, Faculty of Pharmacy, Alexandria University. On the day before the pharmacokinetic study, food was withheld overnight. On the next morning, animals were transferred to metabolic cages to conduct the pharmacokinetic experiments. Serial blood samples were collected at $0.50,0.75,0.92,1.33,2.0,3.5,6.0,8.0$, 24.0, 48.0, and $72.0 \mathrm{~h}$ after oral PSZ dose using retroorbital sampling. Plasma was separated by centrifugation of the blood at $\sim 2500 \times \mathrm{g}$ for $3 \mathrm{~min}$. The samples were kept at $-20^{\circ} \mathrm{C}$ until analysis time.

2.8. Data and Statistical Analysis. Noncompartmental methods were applied to calculate the pharmacokinetic parameters. The elimination rate constant $(\lambda z)$ was calculated by subjecting the plasma concentrations in the terminal phase to linear regression analysis. $t(1 / 2)$ was calculated using the equation $t(1 / 2)=0.693 / \lambda z$. $\mathrm{AUC}_{0-\infty}$ was calculated using the combined log-linear trapezoidal rule from time $0 \mathrm{~h}$ after dose to the time of the last measured concentration, plus the quotient of the last measured concentration divided by $\lambda z$. The concentration at time $0 \mathrm{~h}$ after i.v. dosing $\left(C_{\mathrm{o}}\right)$ was estimated by back extrapolation of the log-linear regression line using the first three measured plasma concentrations to time 0 . The clearance was calculated as the quotient of dose to $\mathrm{AUC}_{0-\infty}$. All compiled data were reported as mean $\pm \mathrm{SD}$ unless otherwise indicated.

\section{Results}

VCR, PSZ, and ITZ eluted at retention times 5.9, 8.3, and 10.4 min, respectively (Figure 1). The total analysis run time was $\sim 11 \mathrm{~min}$. The three peaks were almost symmetrical with excellent baseline separation and no interferences from endogenous substances in plasma. The column separation factor $(\alpha)$ and resolution factor for VCR and PSZ were calculated to be 1.58 and 14.5 for VCR and 1.32 and 7.95 for PSZ, respectively. The column capacity factors $\left(K^{\prime}\right)$ for VCR, PSZ, and ITZ were calculated to be $2.43,3.83$, and 5.05, respectively.

The VCR extraction efficiency recovery was found to be $75.7 \pm 5.4 \%$ while PSZ and ITZ showed $103.9 \pm 3.1 \%$ and $103.6 \pm 5.4 \%(\sim 100 \%)$ recovery, respectively. The assay linearity for VCR and PSZ calculated by measuring the peak area ratios of analyte: internal standard within the concentration range of 50 to $5000 \mathrm{ng} / \mathrm{mL}$ showed high linearity with a mean $r^{2} \geq 0.997$ for both drugs (Figure 2). The mean weighted slope and intercept were found to be $0.0007 \pm 5.09 \times 10^{-5}$ and $0.315 \pm 0.375$ for PSZ, respectively, and $0.0004 \pm 0.0002$ and $-0.002 \pm 0.0037$ for VCR, respectively.

The validation data showed the assay to be sensitive, accurate, and precise, with the intraday and interday CV\% values less than or equal to $13.2 \%$ and $8.78 \%$ for both drugs, respectively (Table 1 ). The mean interday error was less than $13.1 \%$ for both drugs. Since both CV\% of interday and intraday assessment and interday mean error yielded values less than $20 \%$ at the lowest concentration tested, the lower

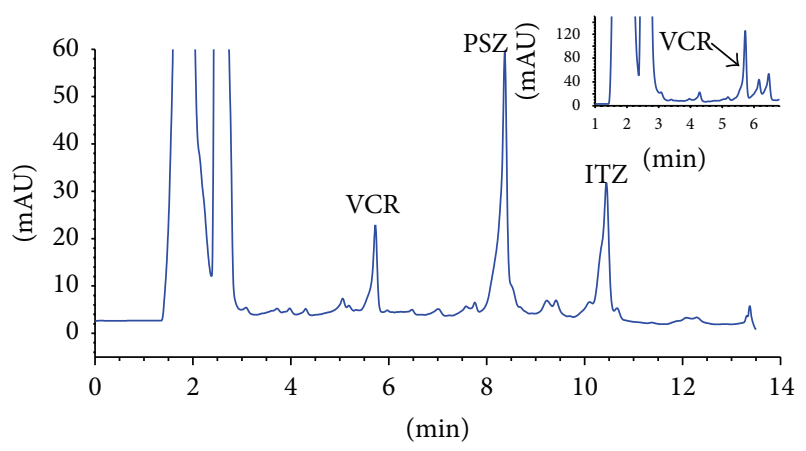

(a)

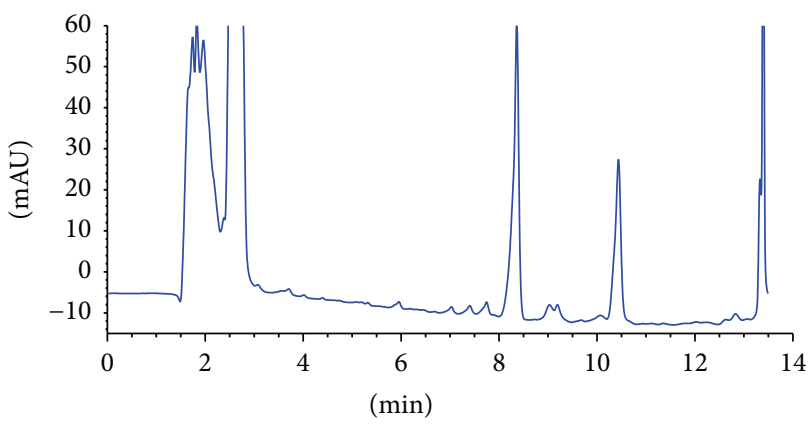

(b)

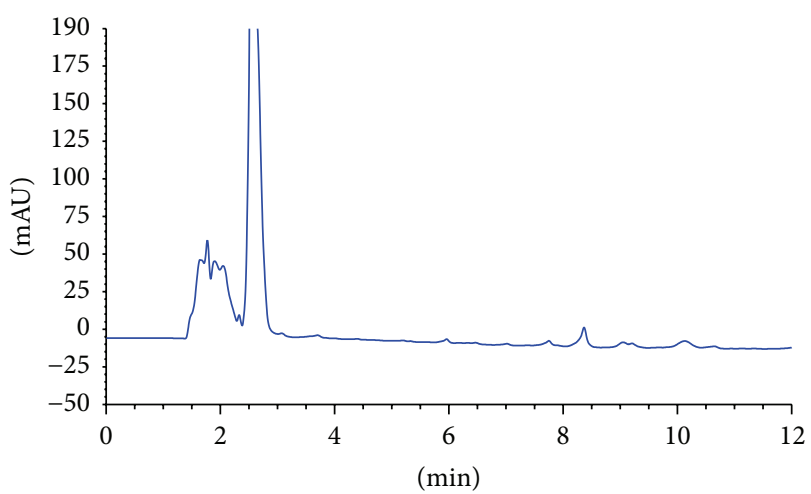

(c)

FIGURE 1: Chromatogram of (a) rat plasma spiked with $2500 \mathrm{ng} / \mathrm{mL}$ of VCR and PSZ, (b) rat plasma obtained after $6 \mathrm{~h}$ of oral PSZ dosing, and (c) blank rat plasma measured at $262 \mathrm{~nm}$. The inset shows a section of a chromatogram for rat plasma spiked with $2500 \mathrm{ng} / \mathrm{mL}$ of VCR measured at $220 \mathrm{~nm}$.

limit of quantitation (LLQ) based on $0.2 \mathrm{~mL}$ of rat plasma was $50 \mathrm{ng} / \mathrm{mL}$ for both drugs.

In both rats dosed with $40 \mathrm{mg} / \mathrm{Kg}$ PSZ orally followed by $0.1 \mathrm{mg} / \mathrm{Kg}$ VCR i.v. $0.5 \mathrm{~h}$ later, the PSZ showed higher plasma concentrations than VCR at all time points (Figure 3). The PSZ Cmax for the two rats were 2344 and $1056 \mathrm{ng} / \mathrm{mL}$ and the VCR $C_{\mathrm{o}}$ were 376 and $228 \mathrm{ng} / \mathrm{mL}$, respectively. The PSZ AUC ${ }_{0-\infty}$ were 206459 and $67744 \mathrm{ng} \cdot \mathrm{h} / \mathrm{mL}$, whereas the VCR $\mathrm{AUC}_{0-\infty}$ were 2347 and $2568 \mathrm{ng} \cdot \mathrm{h} / \mathrm{mL}$ for rat 1 and rat 2, respectively. The PSZ tmax was found to be 8.4 and $7.8 \mathrm{~h}$ for both rats 1 and 2, respectively. The VCR clearance and half-life were calculated to be $0.043 \mathrm{~L} / \mathrm{h} / \mathrm{Kg}$ and $19.2 \mathrm{~h}$ for rat 1 and $0.038 \mathrm{~L} / \mathrm{h} / \mathrm{Kg}$ and $14.8 \mathrm{~h}$ for rat 2 , respectively. 
TABLE 1: Precision and accuracy for the determination of PSZ and VCR in rat plasma using the proposed HPLC-DAD method.

\begin{tabular}{lccccccc}
\hline $\begin{array}{l}\text { Nominal } \\
\text { concentration } \\
\mathrm{ng} / \mathrm{mL}\end{array}$ & Drug & \multicolumn{3}{c}{ Intraday mean \pm SD (intraday CV\%) } & $\begin{array}{c}\text { Interday mean } \pm \\
\text { SD, ng/mL }\end{array}$ & $\begin{array}{c}\text { Interday } \\
\text { CV\% }\end{array}$ & $\begin{array}{c}\text { Interday } \\
\text { mean error\% }\end{array}$ \\
\hline \multirow{2}{*}{50} & PSZ & $57.3 \pm 10.5(18.2)$ & $54.9 \pm 9.54(17.4)$ & $57.4 \pm 0.86(1.49)$ & $56.5 \pm 0.05$ & 1.36 & 13.1 \\
& VCR & $50.3 \pm 5.99(11.9)$ & $56.2 \pm 2.21(3.93)$ & $47.3 \pm 3.07(6.48)$ & $51.3 \pm 4.5$ & 8.78 & 2.53 \\
\hline \multirow{2}{*}{500} & PSZ & $539 \pm 29.8(5.54)$ & $516 \pm 68.3(13.2)$ & $520 \pm 32.1(6.18)$ & $524 \pm 12.0$ & 2.28 & 4.99 \\
& VCR & $528 \pm 27.5(5.21)$ & $495 \pm 17.4(3.50)$ & $540 \pm 56.9(10.5)$ & $521 \pm 23.0$ & 4.41 & 4.25 \\
\hline \multirow{2}{*}{2500} & PSZ & $2460 \pm 383(15.6)$ & $2413 \pm 127(5.25)$ & $2579 \pm 270(10.5)$ & $2483 \pm 85.7$ & 3.45 & -0.65 \\
& VCR & $2494 \pm 282(11.3)$ & $2646 \pm 186(7.03)$ & $2476 \pm 264(10.7)$ & $2539 \pm 93.6$ & 3.69 & 1.54 \\
\hline
\end{tabular}
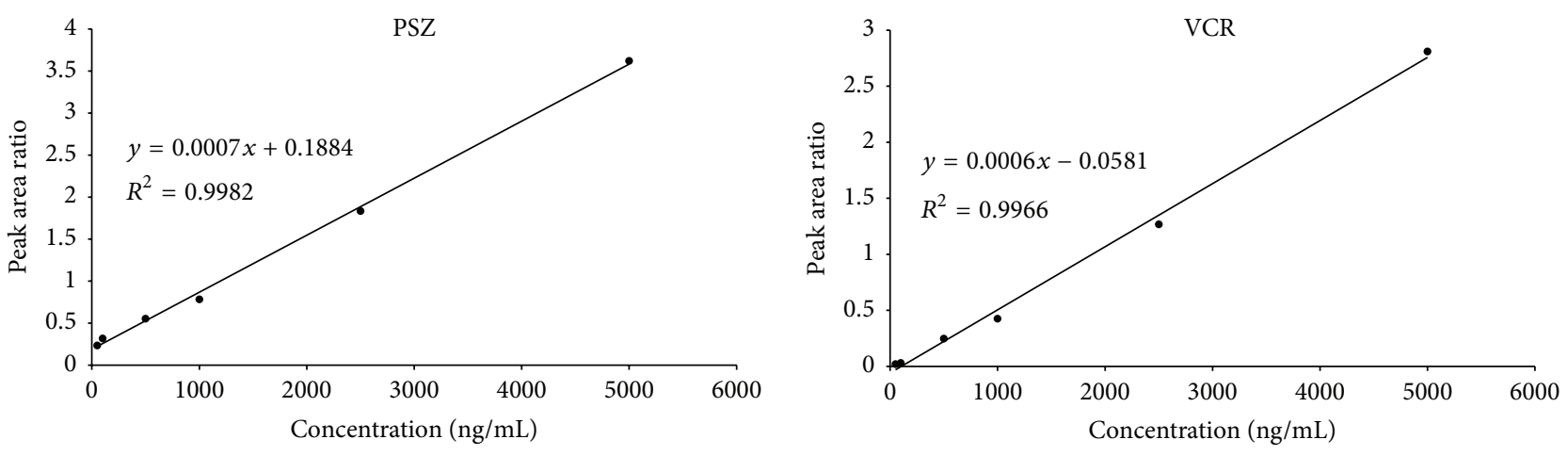

FIGURE 2: Linearity and regression for the determination of PSZ and VCR in rat plasma.
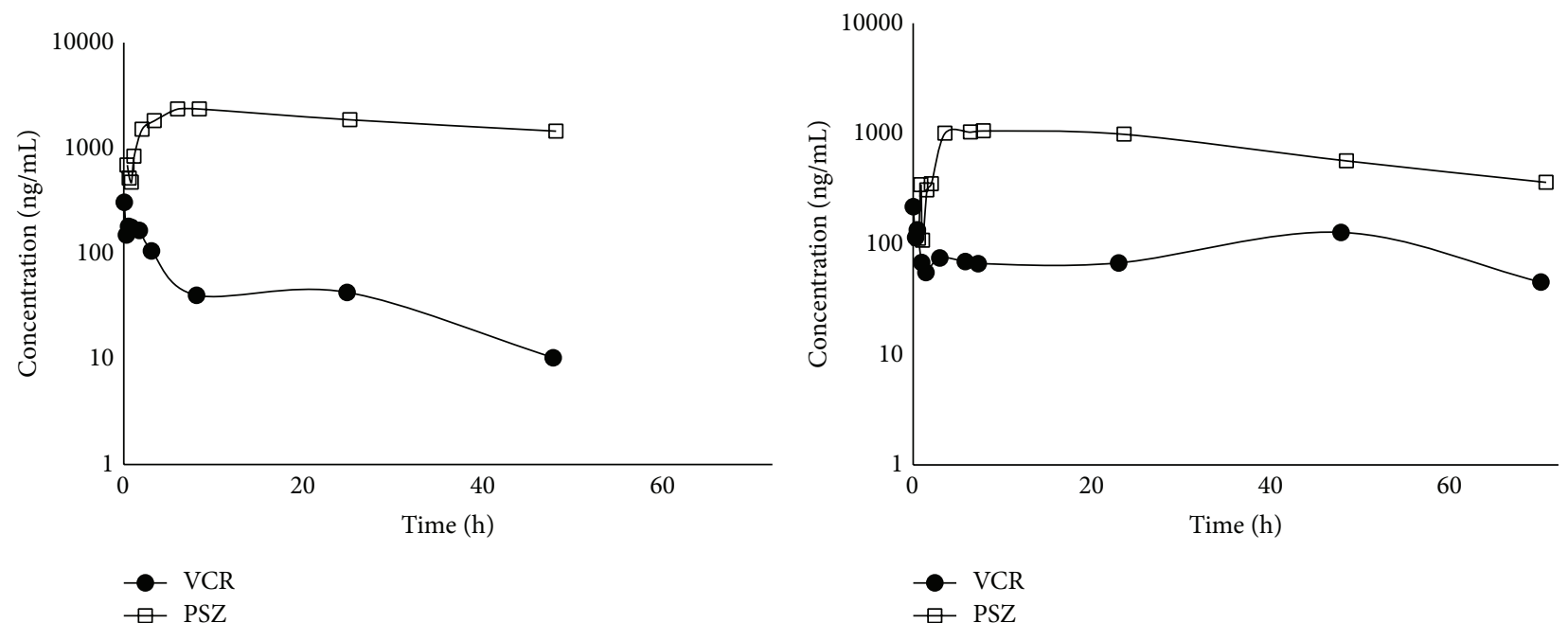

FIgURE 3: Plasma concentration versus time curves for PSZ and VCR in two rats that were given $40 \mathrm{mg} / \mathrm{kg}$ PSZ orally followed by i.v. dosing of $0.1 \mathrm{mg} / \mathrm{kg}$ VCR 30 minutes later.

The assay managed to measure the plasma concentrations for both drugs up to $72 \mathrm{~h}$ after dose.

\section{Discussion}

This paper demonstrates an easy, rapid, sensitive HPLC assay for the simultaneous determination of VCR and PSZ in rat plasma. It successfully measures their plasma concentrations and calculates their PK parameters up to $72 \mathrm{~h}$ after dose. It is worth mentioning that the assay was applied by 3 different analysts on two different HPLC apparatus and yielded similar results with minor changes in retention times and total runtime. The assay was also successfully applied to determine both drugs' concentrations in other matrices, rat's liver tissue homogenate, hyperlipidemic rat's plasma, and liver tissue homogenate, in addition to Sorenson buffer $(\mathrm{pH}=7.4)$, with excellent linearity and same limit of quantification (data not shown).

During assay optimization, the authors utilized the exact chromatographic conditions that they recently published for 
the HPLC determination of PSZ in bulk form and suspension dosage form [29]. However, HC-C18 instead of Zorbax SBC18 column was utilized and HC-C18 guard column was added. Despite the fact that VCR was detected at $262 \mathrm{~nm}$ (Figure 1), it showed better sensitivity and yield at the short wavelength $220 \mathrm{~nm}$. This demonstrates the importance of the multiple wavelength detector (DAD) which offers the advantage of measuring each analyte at its optimum wavelength, thus improving sensitivity.

During the optimization of the extraction procedures, the authors tried the direct protein precipitation method and liquid extraction using diethyl ether, ethyl acetate, or methylene chloride. Both direct protein precipitation and diethyl ether extraction procedures showed similar recoveries. However, the extraction procedure was preferred to protect the column materials and for the ease of the evaporation step in vacuo compared to the direct protein precipitation one. Solid phase extraction was not attempted due to its relatively higher cost when working with large number of samples within the future planned PK studies.

The PSZ and VCR retention times using our simultaneous assay lie within the reported retention times for PSZ and VCR, respectively [13-18]. There is a slight interference from an endogenous plasma peak in the PSZ peak; this interference resulted in the fact that we could not quantify the PSZ peak accurately below the $50 \mathrm{ng} / \mathrm{mL}$ concentration; however, as mentioned before, it did not interfere with any of the validation parameters within our concentration range 50$5000 \mathrm{ng} / \mathrm{mL}$.

The pharmacokinetics parameters reported for PSZ and VCR in rat were compared to the only two similar manuscripts found in literature [30,31]. The VCR clearance came within the lower border of that reporting $0.12 \pm$ $0.08 \mathrm{~L} / \mathrm{h} / \mathrm{Kg}$ and showed similar terminal phase half-life to that reporting $14.3 \pm 6.3 \mathrm{~h}$ [30]. Similarly, PSZ mean AUC and $C_{\max }$ were close to those reported previously [31]. The slight variability could be due to the concomitant administration with VCR or difference between our SD rats and the Crl : CD $\mathrm{BR}$ reported [32]. It is worth mentioning that, for the future planned elaborated VCR-PSZ drug interaction study, the design of the drug interaction needs to be modified to mimic the actual conditions occurring in humans. However, for the purpose of proving the appropriateness of the analytical technique to study such interaction, we successfully dosed only a single dose of each drug and managed to measure it using our DAD detector for up to $72 \mathrm{~h}$ which is advantageous over similar HPLC-DAD assays reported for each drug alone.

\section{Conclusion}

This paper describes the first validated method for the simultaneous determination of posaconazole and vincristine in rat plasma. The proposed HPLC-DAD method has been applied in the investigation of their pharmacokinetics in rats up to $72 \mathrm{~h}$ after dose. The obtained pharmacokinetics parameters for posaconazole and vincristine are in good agreement with those reported in previous reports. The developed method is simple, sensitive, and suitable for the estimation of both drugs in comprehensive drug-drug interaction pharmacokinetic studies in rats.

\section{Conflict of Interests}

The authors declare no financial, personal, or organizational conflict of interests.

\section{Acknowledgment}

The study was funded by Science \& Technology Development Fund (STDF) (Project ID: 5575), Ministry of State for Scientific Research, Egypt.

\section{References}

[1] S. C. Sweetman, Ed., Martindale-The Complete Drug Reference, The Pharmaceutical Press, London, UK, 36th edition, 2009.

[2] D. A. Hamdy, S. El-Salem, H. El-Geed, and M. Zaidan, "Posaconazole, a prophylactic therapy in patients with haematological cancer: drug use evaluation study," European Journal of Hospital Pharmacy: Science and Practice, vol. 20, no. 4, pp. 223226, 2013.

[3] R. M. van Schie, R. J. M. Brüggemann, P. M. Hoogerbrugge, and D. M. W. M. te Loo, "Effect of azole antifungal therapy on vincristine toxicity in childhood acute lymphoblastic leukaemia," Journal of Antimicrobial Chemotherapy, vol. 66, no. 8, pp. 18531856, 2011.

[4] D. A. Hamdy, H. El-Geed, S. El-Salem, and M. Zaidan, "Posaconazole-vincristine coadministration triggers seizure in a young female adult: a case report," Case Reports in Hematology, vol. 2012, Article ID 343742, 3 pages, 2012.

[5] H.-W. Liao, S.-W. Lin, U.-I. Wu, and C.-H. Kuo, "Rapid and sensitive determination of posaconazole in patient plasma by capillary electrophoresis with field-amplified sample stacking," Journal of Chromatography A, vol. 1226, pp. 48-54, 2012.

[6] W. Neubauer, A. König, R. Bolek et al., "Determination of the antifungal agent posaconazole in human serum by HPLC with parallel column-switching technique," Journal of Chromatography B: Analytical Technologies in the Biomedical and Life Sciences, vol. 877, no. 24, pp. 2493-2498, 2009.

[7] J. X. Shen, G. Krishna, and R. N. Hayes, "A sensitive liquid chromatography and mass spectrometry method for the determination of posaconazole in human plasma," Journal of Pharmaceutical and Biomedical Analysis, vol. 43, no. 1, pp. 228236, 2007.

[8] J. M. Cunliffe, C. F. Noren, R. N. Hayes, R. P. Clement, and J. X. Shen, "A high-throughput LC-MS/MS method for the quantitation of posaconazole in human plasma: implementing fused core silica liquid chromatography," Journal of Pharmaceutical and Biomedical Analysis, vol. 50, no. 1, pp. 46-52, 2009.

[9] S.-C. Lin, H.-Y. Liu, S.-W. Lin et al., "Simultaneous determination of triazole antifungal drugs in human plasma by sweeping-micellar electrokinetic chromatography," Analytical and Bioanalytical Chemistry, vol. 404, no. 1, pp. 217-228, 2012.

[10] A. Chahbouni, A. J. Wilhelm, J. C. G. Den Burger, A. Sinjewel, and R. M. Vos, "Validated liquid chromatography-tandem mass spectroscopy method for the simultaneous quantification of four antimycotic agents in human serum," Therapeutic Drug Monitoring, vol. 32, no. 4, pp. 453-457, 2010. 
[11] J.-F. Jourdil, J. Tonini, and F. Stanke-Labesque, "Simultaneous quantitation of azole antifungals, antibiotics, imatinib, and raltegravir in human plasma by two-dimensional highperformance liquid chromatography-tandem mass spectrometry," Journal of Chromatography B, vol. 919-920, pp. 1-9, 2013.

[12] S. L. Buckner, M. M. Ceesay, A. Pagliuca, P. E. Morgan, and R. J. Flanagan, "Measurement of posaconazole, itraconazole, and hydroxyitraconazole in plasma/serum by high-performance liquid chromatography with fluorescence detection," Therapeutic Drug Monitoring, vol. 33, no. 6, pp. 735-741, 2011.

[13] S. Chhun, E. Rey, A. Tran, O. Lortholary, G. Pons, and V. Jullien, "Simultaneous quantification of voriconazole and posaconazole in human plasma by high-performance liquid chromatography with ultra-violet detection," Journal of Chromatography B: Analytical Technologies in the Biomedical and Life Sciences, vol. 852, no. 1-2, pp. 223-228, 2007.

[14] J.-B. Gordien, A. Pigneux, S. Vigouroux et al., "Simultaneous determination of five systemic azoles in plasma by highperformance liquid chromatography with ultraviolet detection," Journal of Pharmaceutical and Biomedical Analysis, vol. 50, no. 5, pp. 932-938, 2009.

[15] M. Zhang, G. A. Moore, M. L. Barclay, and E. J. Begg, "A simple high-performance liquid chromatography method for simultaneous determination of three triazole antifungals in human plasma," Antimicrobial Agents and Chemotherapy, vol. 57, no. 1, pp. 484-489, 2013.

[16] C. P. W. G. M. Verweij-van Wissen, D. M. Burger, P. E. Verweij, R. E. Aarnoutse, and R. J. M. Brüggemann, "Simultaneous determination of the azoles voriconazole, posaconazole, isavuconazole, itraconazole and its metabolite hydroxy-itraconazole in human plasma by reversed phase ultra-performance liquid chromatography with ultraviolet detection," Journal of Chromatography B, vol. 887-888, pp. 79-84, 2012.

[17] L. Embree, K. A. Gelmon, A. W. Tolcher et al., "Validation of a high-performance liquid chromatographic assay method for quantification of total vincristine sulfate in human plasma following administration of vincristine sulfate liposome injection," Journal of Pharmaceutical and Biomedical Analysis, vol. 16, no. 4, pp. 675-687, 1997.

[18] J. Chen, H. He, S. Li, and Q. Shen, "An HPLC method for the pharmacokinetic study of vincristine sulfate-loaded PLGAPEG nanoparticle formulations after injection to rats," Journal of Chromatography B, vol. 879, no. 21, pp. 1967-1972, 2011.

[19] F. Yang, H. Wang, M. Liu, P. Hu, and J. Jiang, "Determination of free and total vincristine in human plasma after intravenous administration of vincristine sulfate liposome injection using ultra-high performance liquid chromatography tandem mass spectrometry," Journal of Chromatography A, vol. 1275, pp. 6169, 2013.

[20] J. I. Lee, J. M. Skolnik, J. S. Barrett, and P. C. Adamson, "A sensitive and selective liquid chromatography-tandem mass spectrometry method for the simultaneous quantification of actinomycin-D and vincristine in children with cancer," Journal of Mass Spectrometry, vol. 42, no. 6, pp. 761-770, 2007.

[21] J. B. Dennison, J. L. Renbarger, D. O. Walterhouse, D. R. Jones, and S. D. Hall, "Quantification of vincristine and its major metabolite in human plasma by high-performance liquid chromatography/tandem mass spectrometry," Therapeutic Drug Monitoring, vol. 30, no. 3, pp. 357-364, 2008.

[22] C. W. N. Damen, T. Israëls, H. N. Caron, J. H. M. Schellens, H. Rosing, and J. H. Beijnen, "Validated assay for the simultaneous quantification of total vincristine and actinomycin-D concentrations in human EDTA plasma and of vincristine concentrations in human plasma ultrafiltrate by high-performance liquid chromatography coupled with tandem mass spectrometry," Rapid Communications in Mass Spectrometry, vol. 23, no. 6, pp. 763-774, 2009.

[23] G. Ling, P. Zhang, J. Sun et al., "An LC-MS/MS method for simultaneous determination of vincristine and verapamil in rat plasma after oral administration of a dual agent formulation," Biomedical Chromatography, vol. 25, no. 9, pp. 963-969, 2011.

[24] C. W. N. Damen, H. Rosing, J. H. M. Schellens, and J. H. Beijnen, "Application of dried blood spots combined with highperformance liquid chromatography coupled with electrospray ionisation tandem mass spectrometry for simultaneous quantification of vincristine and actinomycin-D," Analytical and Bioanalytical Chemistry, vol. 394, no. 4, pp. 1171-1182, 2009.

[25] E. Groninger, P. Koopmans, W. Kamps, S. De Graaf, and D. Uges, "An automated HPLC method to determine intracellular vincristine concentrations in mononuclear cells of children with acute lymphoblastic leukemia," Therapeutic Drug Monitoring, vol. 25, no. 4, pp. 441-446, 2003.

[26] W. Jin and L. Jiang, "Study of uptake kinetics of vincristine for human erythrocytes by capillary zone electrophoresis with electrochemical detection," Analytica Chimica Acta, vol. 461, no. 1, pp. 117-121, 2002.

[27] A. A. Nomeir, P. Kumari, M. J. Hilbert et al., "Pharmacokinetics of SCH 56592, a new azole broad-spectrum antifungal agent, in mice, rats, rabbits, dogs, and cynomolgus monkeys," Antimicrobial Agents and Chemotherapy, vol. 44, no. 3, pp. 727-731, 2000.

[28] X. J. Zhou, M. Martin, M. Placidi, J. P. Cano, and R. Rahmani, "In vivo and in vitro pharmacokinetics and metabolism of vincaalkaloids in rat II. Vinblastine and Vincristine," European Journal of Drug Metabolism and Pharmacokinetics, vol. 15, no. 4, pp. 323-332, 1990.

[29] D. A. Hamdy and T. S. Belal, "A comparative study of newly developed HPLC-DAD and UHPLC-UV assays for the determination of posaconazole in bulk powder and suspension dosage form," Journal of Analytical Methods in Chemistry, vol. 2014, Article ID 241035, 7 pages, 2014.

[30] X. J. Zhou, M. Martin, M. Placidi, J. P. Cano, and R. Rahmani, "In vivo and in vitro pharmacokinetics and metabolism of vincaalkaloids in rat II. Vinblastine and Vincristine," European Journal of Drug Metabolism and Pharmacokinetics, vol. 15, no. 4, pp. 323-332, 1990.

[31] A. A. Nomeir, P. Kumari, M. J. Hilbert et al., "Pharmacokinetics of SCH 56592, a new azole broad-spectrum antifungal agent, in mice, rats, rabbits, dogs, and cynomolgus monkeys," Antimicrobial Agents and Chemotherapy, vol. 44, no. 3, pp. 727-731, 2000.

[32] J. C. Pattersen, "A 2-year comparison study of Crl:CD BR and Hsd:Sprague-Dawley SD rats," Fundamental and Applied Toxicology, vol. 33, pp. 196-211, 1996. 

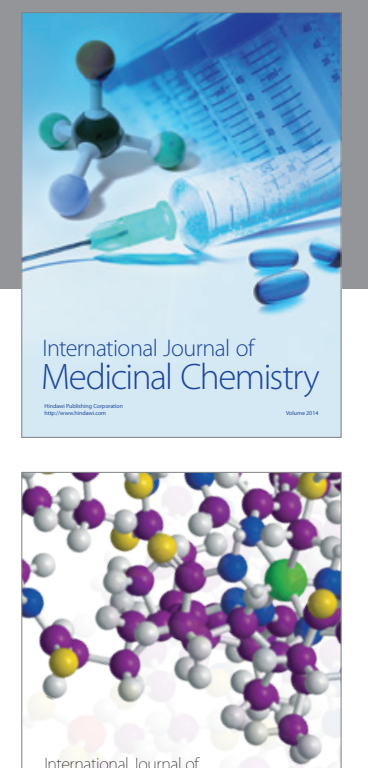

\section{Carbohydrate} Chemistry

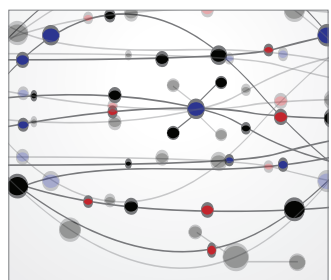

The Scientific World Journal
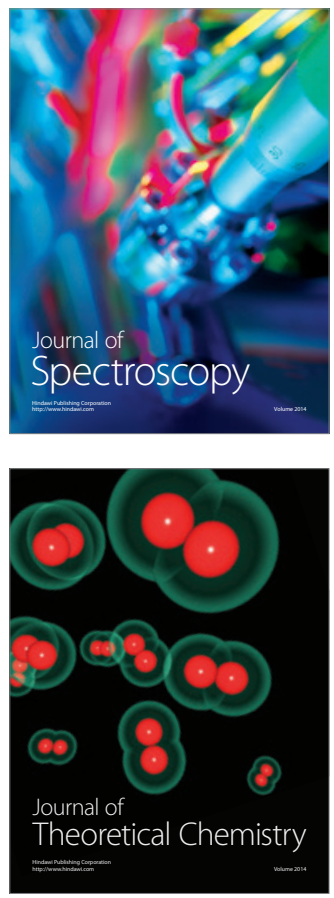
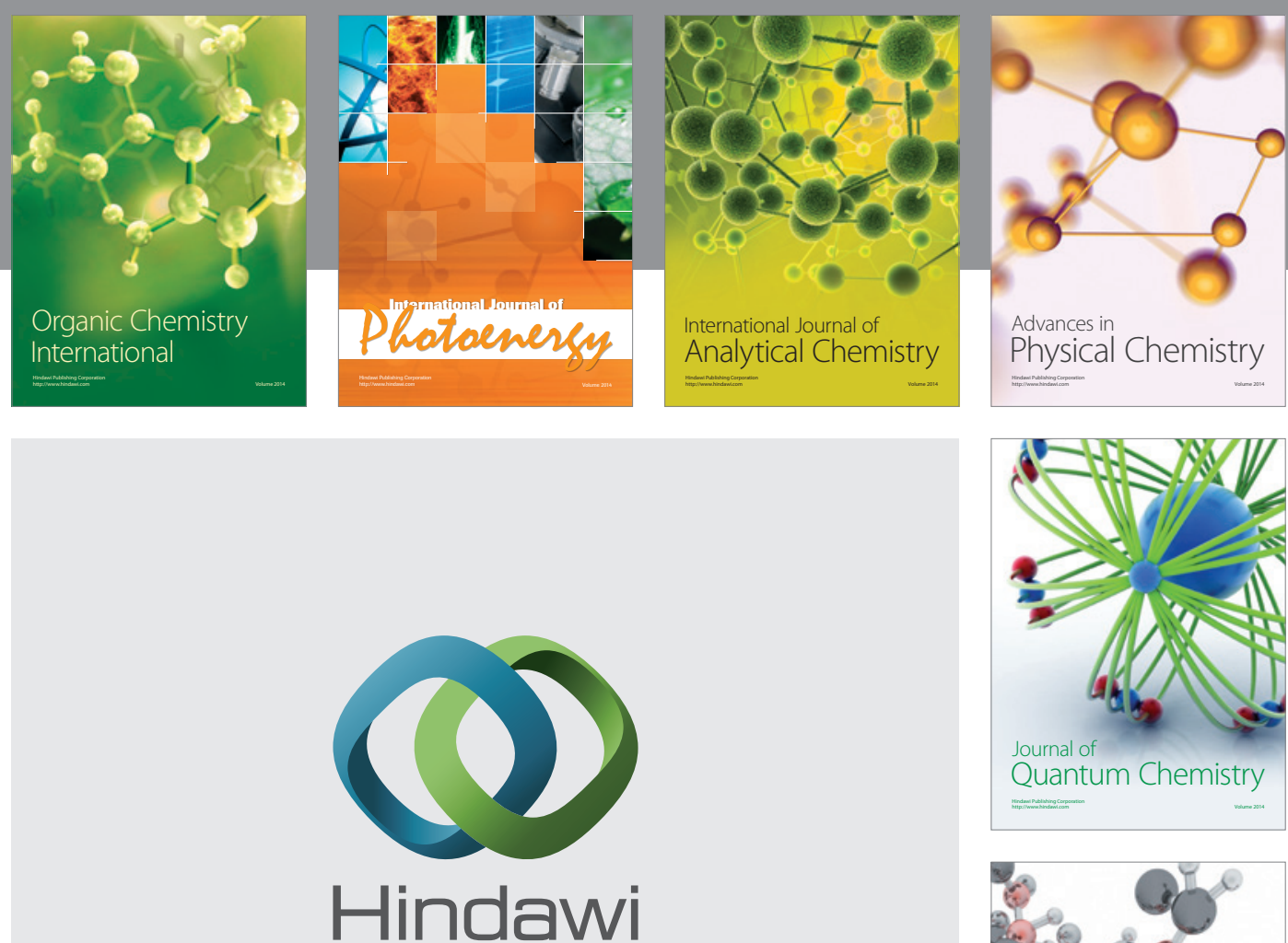

Submit your manuscripts at

http://www.hindawi.com

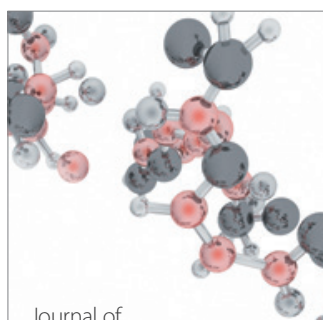

Analytical Methods

in Chemistry

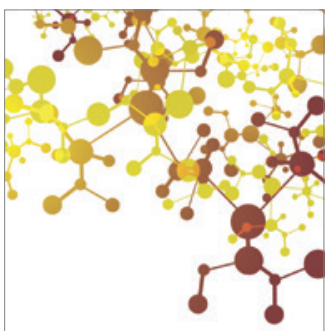

Journal of

Applied Chemistry

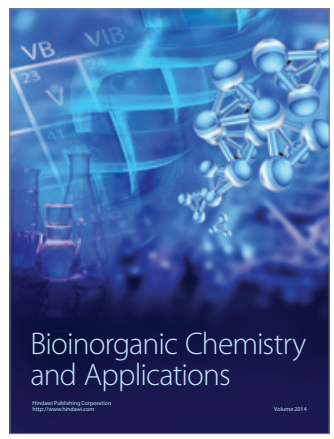

Inorganic Chemistry
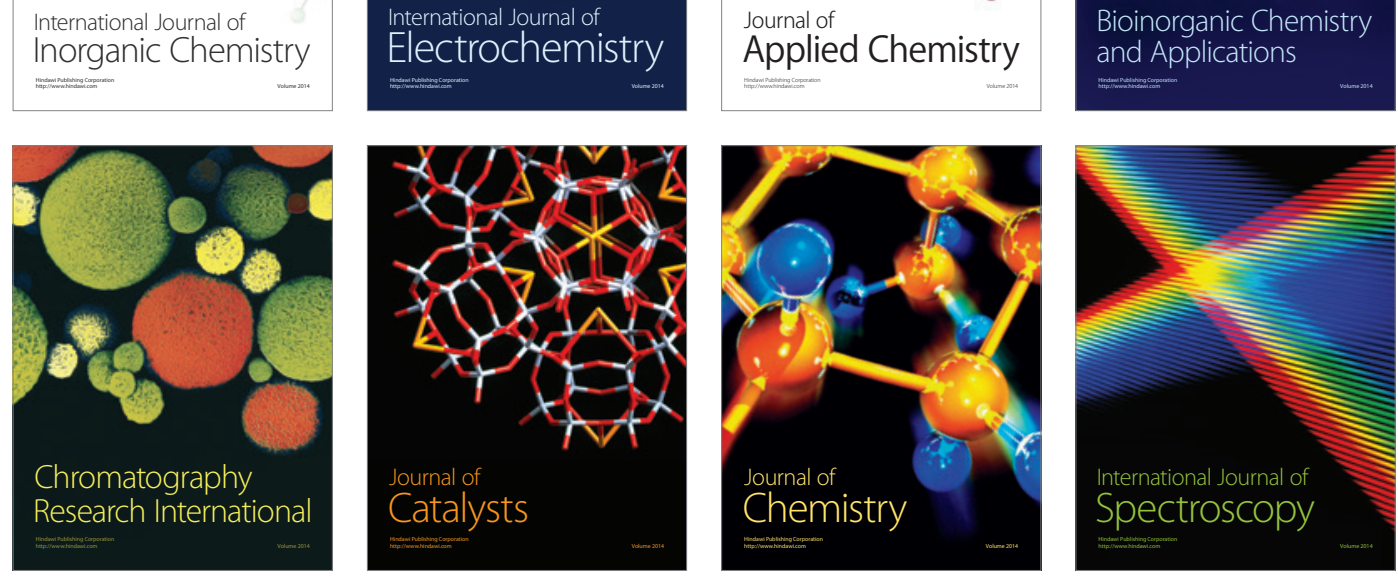